\title{
Research Article \\ Effect of Energy Drinks on the Inorganic Composition of a Composite Resin Material
}

\author{
Lara Pepita de Souza Oliveira ${ }^{1}$, Diego Ferreira Regalado², Danielson Guedes Pontes ${ }^{2 *}$, Cláudia Cândida Silva ${ }^{3}$, João \\ Víctor Monteiro de Albuquerque $e^{3}$ and Hugo Felipe do Vale ${ }^{4}$
}

${ }^{I}$ Dental Materials, Post-Graduate Student, PPGO, Faculty of Dentistry, Federal University of Amazonas, Manaus, Brazil

${ }^{2}$ Operative Dentistry, State University of Amazonas, Manaus, Amazonas, Brazil

${ }^{3}$ Chemical Engineering, State University of Amazonas, Manaus, Amazonas, Brazil

${ }^{4}$ Periodontics, State University of Amazonas, Manaus, Amazonas, Brazil

\section{ARTICLE INFO}

Article history:

Received: 6 July, 2020

Accepted: 18 July, 2020

Published: 25 July, 2020

Keywords:

Composite resins

energy drinks

inorganic composition

\begin{abstract}
A B S T R A C T
Composite resins are used in Dentistry to perform direct aesthetic restorations, and are a material whose properties can be influenced by the diet of the individual, especially in the face of the action of beverages with acid $\mathrm{pH}$, such as energy drinks. The aim of this in vitro study was to evaluate the effect of two energy beverages on the chemical composition of a nanoparticulate composite resin, at two-time intervals. Filtek Z350XT (3M/ESPE) composite resin was used to produce thirty-six specimens (discs) of $6.0 \mathrm{~mm} \times 1.5 \mathrm{~mm}$ dimensions. The specimens were initially immersed in distilled water for $24 \mathrm{~h}$ at $37^{\circ} \mathrm{C}$ and then randomly divided into two groups ( $\mathrm{n}=18$ ); according to the immersion time: 1 month (T1) and 3 months (T2); and in three subgroups $(n=6)$ referring to immersion solutions: distilled water (control) and two energy beverages (RedBull and Monster). The inorganic composition of the specimens was measured by a spectrometry. The data were submitted to two-way ANOVA and Tukey tests. The main inorganic elements of this restorative material were respectively: zirconium $(\mathrm{Zr})$, silicon $(\mathrm{Si})$ and calcium $(\mathrm{Ca})$, which reduced its percentage after immersion time. RedBull was the most active solution, promoting losses of the mineral Si after 1 month of immersion, of $\mathrm{Zr}$, after 3 months, and of $\mathrm{Ca}$ after 1 month and after 3 months. Monster influenced losses only in $\mathrm{Si}$, after 1 month. Distilled water did not induce significant losses. Thus, the two energy beverages reduced the inorganic percentage of the nanoparticulate composite resin evaluated in this research.
\end{abstract}

Introduction

The aesthetics of the smile plays an important role in society, with a composite resin being a widely used dental material for this application, with indication for both anterior and posterior teeth. Its physical and chemical properties are closely related to the quantity and size of their filler components. The higher this percentage, the greater the mechanical strength, microhardness and modulus of elasticity and less contraction of polymerization [1]. However, although manufacturers improve the composition of composite resins, the chemical environment is still an aspect with appreciable influence on the degradation of this material [2]. The hydrophilic characteristics of the resin matrix influence the degree of water sorption and, therefore, acidic drinks can impair the surface integrity of the composite resins, aesthetically and physically, tending to cause erosion on the surface of material, and this degradation is related to the content and distribution of inorganic fillers [2, 3]. Energy drinks are widely consumed, mainly by athletes, to promote well-being and better physical performance, due to the presence of components such as coffee, taurine and glucuronolactone [4-6]. However, the presence of citric acid, high sugar content and low $\mathrm{pH}$ of its composition are harmful to teeth and restorations, if consumed routinely $[6,7]$.

It is relevant to evaluate the effect of acidic beverages, such as energy drinks, on properties of composite resins, such as microhardness, as this,

${ }^{*}$ Correspondence to: Danielson Guedes Pontes, M.D., Ph.D., Operative Dentistry, State University of Amazonas, Manaus, Amazonas, Brazil; Tel: $92988557577 ;$ Email:danielsonpontes@hotmail.com 
when modified, has consequences such as: lower mechanical resistance, increased roughness, biofilm accumulation, surface degradation and marginal infiltration, which also supports the importance of studies evaluating the acid challenge in the resin load, as it is directly associated with mechanical properties [4, 6-11]. The aim of this study was to evaluate whether the inorganic content of a nanoparticulate composite resin solubilizes in the face of the acid challenge of two similar $\mathrm{pH}$ energy drinks, at different immersion times.

\section{Materials and Methods}

An in vitro experimental study was carried out in the city of Manaus, at the Dental Research Laboratory of the State University of Amazonas and data collection at the Research Laboratory of the Crowfoot Group on XRay Methods at the Superior School of Technology. Thirty-six specimens (discs) of a nanoparticulate composite resin Filtek Z350XT (3M/ESPE; California, EUA), shade A3E, were produced with $6.0 \mathrm{~mm}$ (diameter) $\mathrm{x} 1.5 \mathrm{~mm}$ (high) using a incremental technique into the silicon matrix guide. Before the last increment photo-activation, a polyester strip was placed on the material, and a glass slide was pressed, to obtain a flat and homogenous surface (Figure 1). All increments were lightcured using a polymerization unit (Radii Call; SDI - Sidney, Australia), with light intensity of $1.200 \mathrm{~mW} / \mathrm{cm}^{2}$ for 20 seconds. The inorganic composition of the specimens was evaluated using the X-ray fluorescence by wave dispersion equipment (WD-XRF, Rigaku, model Supermini, palladium tube) with exposure time of $200 \mathrm{~s}$ and $200 \mathrm{~W}$ of power. Three different solutions were employed in the present study: distilled water (control), and two energy drinks (Red Bull ${ }^{\mathrm{TM}}$ and Monster ${ }^{\mathrm{TM}}$ ), whose ingredients are present in (Table 1).

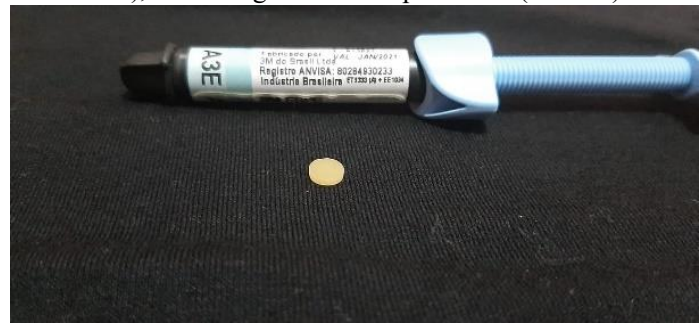

Figure 1: Specimen of the nanoparticulate composite resin Filtek Z350 A3E, brand $3 \mathrm{M}$ ESPE.

Table 1: Composition and manufacturers of tested solutions.

\begin{tabular}{|c|c|c|}
\hline SOLUTION & COMPOSITION & MANUFACTURER \\
\hline Monster & $\begin{array}{l}\text { Carbonated water, sucrose, glucose, citric acid, natural flavors, } 0,4 \% \text { taurine, sodium } \\
\text { citrate, color added, } 0.08 \% \text { panax ginseng root extract, } 0.04 \% \text { L-carnitine L-tartarate, } \\
0,03 \% \text { caffeine, sorbic acid, benzoic acid, niacinamide, sodium chloride, Glycine max } \\
\text { glucuronolactone, inositol, } 0,002 \% \text { guarana seed extract, pyridoxine hydrochloride, } \\
\text { sucralose, riboflavin, maltodextrin, and cyanocobalamin. }\end{array}$ & $\begin{array}{l}\text { Monster Beverage Corporation, Corona, } \\
\text { California; } \\
\mathrm{pH}=3.37\end{array}$ \\
\hline Redbull & $\begin{array}{l}\text { Water, sucrose, glucose, acidity regulators (sodium citrates, magnesium carbonate), } \\
\text { carbon dioxide, acidifier citric acid, } 0.4 \% \text { taurine, } 0.03 \% \text { caffeine, inositol, vitamins } \\
\text { (niacin, pantothenic acid, B6, B12), flavoring, colors (caramel, riboflavin). }\end{array}$ & $\begin{array}{l}\text { Red Bull GmbH, Am Brunnen, Austria; } \\
\mathrm{pH}=3.54\end{array}$ \\
\hline Distilled water & Chemically pure, free from soluble, clear, colourless and odourless & ASFER, São Paulo, Brasil; pH=7.0 \\
\hline Filtek Z350 XT & UDMA, TEGDMA, BisEMA, particle size: 5-20 nm, Zirconia/nanosilica. & 3M ESPE, St. Paul, MN, USA \\
\hline
\end{tabular}

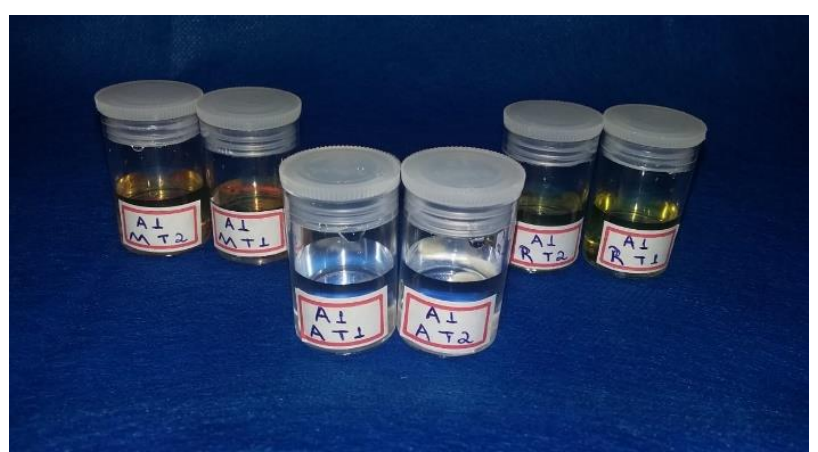

Figure 2: Identification of the sample groups, A1 being the first sample, followed by the identification of the solution and its corresponding immersion cycle.

The chemical analysis was performed after all the specimens have been immersed in distilled water and kept at $37^{\circ} \mathrm{C}$ for $24 \mathrm{~h}$ (T0-baseline), to allow the composite resin expansion of after water sorption, a characteristic behavior of this material [10]. Then, the specimens were divided into two groups $(\mathrm{n}=18)$ according immersion time in test solutions: one month (T1) and three months (T2). Afterwards, each group was divided again into three sub-groups $(n=6)$ according to the type of solution: distilled water; RedBull and Monster. Further analysis of the chemical content was conducted at T1 and T2 (Figure 2). The immersion cycles consisted of 24 hours, at a temperature of $37^{\circ} \mathrm{C}$, daily immersion with weekly new solutions changes.
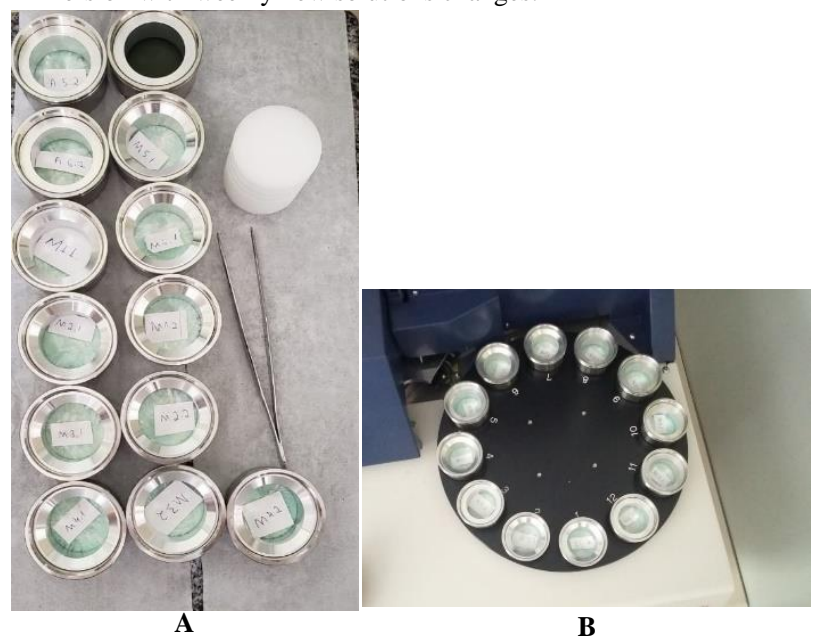

Figure 3: A) Accommodation of the condensation silicone matrices, identified and containing the specimen, in the spectrometer equipment sample holder. B) Specimens positioned in the equipment. 
For chemical quantification after immersion, the specimens were carefully dried with absorbent paper, adapted to the condensation silicone matrices and inserted in the equipment (Figure 3). The data obtained were released to the Spectrometer Status program [12]. This chemical analysis method has already been used in other investigations [13]. For the study, two independent variables were used: immersion solution (distilled water, Red Bull, Monster) and immersion time (1 month and 3 months). The two-factor parametric test (bidirectional ANOVA) for repeated measures was used to assess the influence of time (factor 1, with 2 levels) and immersion solution (factor 2, with 3 levels) on the values of the inorganic concentration present in the 3 main chemical elements found: silicon ( $\mathrm{Si}$ ), zirconium $(\mathrm{Zr})$ and calcium $(\mathrm{Ca})$. The Tukey test was used to identify differences between the media $(\propto=$ $0.05)$.

\section{Results}

The spectrometer identified all the inorganic components present in the samples of the Filtek Z350XT nanoparticulate composite resin, in mg / $\mathrm{cm}^{2}$. The chemical elements found were magnesium, aluminum, silicon, potassium, calcium, iron, zinc and zirconium. In this work, those with the highest percentage were considered: silicon, zirconium and calcium. The mean and standard deviation of the data are contained in (Table 2). The two-way factor analysis of variance (ANOVA) and the Tukey's test were performed to analyze the significance of the factors (time and solution) in the concentration of each element. The Tukey test was performed to analyze the averages between immersion times after 1 month and 3 months in the different solutions (Table 3), and the $p$ values can be seen in (Table 4), which shows the statistical interaction between the solutions at different immersion times for each chemical element. According to statistics, the amount of charge found for the element Silicon, in samples immersed in distilled water, was statistically higher compared to Red Bull $(\mathrm{p}=0.003)$ and Monster $(\mathrm{p}=0.03)$ in the time of 1 month, which indicates there was a loss of this mineral in the samples immersed in energy drinks when compared to the distilled water control solution, with no differences between the different solutions after 3 months.

Table 2: The mean (M) and standard deviation (SD) of the concentrations (in $\mathrm{mg} / \mathrm{cm}^{2}$ ) of the chemical elements as to the solution factor compared to the immersion time factor.

\begin{tabular}{c|c|c|c|c|c}
\hline \multirow{2}{*}{$\begin{array}{c}\text { Chemical } \\
\text { element }\end{array}$} & \multirow{2}{*}{ Solution } & \multicolumn{2}{|c|}{$\mathbf{T}^{\mathbf{1}}$} & \multicolumn{2}{|c}{$\mathbf{T}^{\mathbf{2}}$} \\
\cline { 3 - 6 } Silicon & & $\mathbf{M}$ & SD & M & SD \\
\cline { 2 - 6 } & Distilled water & 0,3632 & 0,032085 & 0,3339 & 0,046274 \\
\cline { 2 - 6 } & Redbull & 0,2850 & 0,04624 & 0,3258 & 0,014742 \\
\cline { 2 - 6 } & Monster & 0,3114 & 0,016795 & 0,3296 & 0,03402 \\
\hline \multirow{4}{*}{ Zirconium } & Distilled water & 0,8570 & 0,037489 & 0,9671 & 0,117383 \\
\cline { 2 - 6 } & Redbull & 0,8734 & 0,077916 & 0,7989 & 0,053882 \\
\cline { 2 - 6 } & Monster & 0,8485 & 0,04071 & 0,8884 & 0,058173 \\
\hline \multirow{4}{*}{ Calcium } & Distilled water & 0,2073 & 0,009312 & 0,2164 & 0,014931 \\
\cline { 2 - 6 } & Redbull & 0,1848 & 0,019613 & 0,1899 & 0,00974 \\
\cline { 2 - 6 } & Monster & 0,1963 & 0,011584 & 0,2014 & 0,01034 \\
\hline
\end{tabular}

For the Zirconium element, there was no difference in the amount of charge over the 1 month time between the solutions; however, after 3 months, in the Red Bull energy drink, it was found in a significantly lower amount compared to distilled water $(p=0.0006)$. There were no significant changes in this element in the samples immersed in Monster, both between the times and in relation to the other solutions. The calcium concentration found in the Red Bull energy drink was statistically lower in $\mathrm{T} 1(\mathrm{p}=0.01)$ and especially in $\mathrm{T} 2(\mathrm{p}=0.003)$, when compared to the control solution. No statistical changes for this element in the samples immersed in Red Bull. From the time $\mathrm{T}^{1}$ to $\mathrm{T}^{2}$, the statistical changes found were related to $\mathrm{Si}$ in the Red Bull energy drink ( $\mathrm{p}=0.05)$, as shown in (Table 4)

Table 3: Statistical differences represented by the Tukey / two way ANOVA test between the factors of time and immersion solution for each element.

\begin{tabular}{c|c|c|c|c|c|c|c|c}
\hline \multicolumn{3}{c|}{ Silicon } & \multicolumn{3}{c|}{ Zirconium } & \multicolumn{3}{c}{ Calcium } \\
\hline Solution & $\mathrm{T} 1$ & $\mathrm{~T} 2$ & Solução & $\mathrm{T} 1$ & $\mathrm{~T} 2$ & Solução & $\mathrm{T} 1$ & $\mathrm{~T} 2$ \\
\hline Water & $\mathrm{Aa}$ & $\mathrm{Aa}$ & Agua & $\mathrm{Aa}$ & $\mathrm{Ab}$ & Agua & $\mathrm{Aa}$ & $\mathrm{Aa}$ \\
\hline Redbull & $\mathrm{Bb}$ & $\mathrm{Aa}$ & Redbull & $\mathrm{Aa}$ & $\mathrm{Ba}$ & Redbull & $\mathrm{Ba}$ & $\mathrm{Ba}$ \\
\hline Monster & $\mathrm{Ba}$ & $\mathrm{Aa}$ & Monster & $\mathrm{Aa}$ & $\mathrm{Aba}$ & Monster & $\mathrm{Aba}$ & $\mathrm{Aba}$ \\
\hline
\end{tabular}

*Different lowercase letters in the line and different uppercase letters in the column mean statistical difference by the two way ANOVA / Tukey test.

Table 4: $p$ values for the interaction between solutions and times for each chemical element ( $p$ values are for the two-way ANOVA test at $\alpha=0.05$ level of significance).

\begin{tabular}{c|c|c|c|c|c|c}
\hline \multirow{2}{*}{ Solution } & \multicolumn{5}{|c}{ Immersion times according to the element } \\
\cline { 2 - 7 } & Silicon & \multicolumn{2}{c}{ Zirconium } & \multicolumn{2}{c}{ Calcium } \\
\cline { 2 - 7 } & $\mathrm{T}^{1}$ & $\mathrm{~T}^{2}$ & $\mathrm{~T}^{1}$ & $\mathrm{~T}^{2}$ & $\mathrm{~T}^{1}$ & $\mathrm{~T}^{\mathbf{2}}$ \\
\hline Water x Redbull & 0,0034 & 0,9114 & 0,9127 & 0,0006 & 0,0146 & 0,0039 \\
\hline Water x Monster & 0,0347 & 0,9736 & 0,9755 & 0,1410 & 0,3248 & 0,1313 \\
\hline Redbull x Monster & 0,3859 & 0,9803 & 0,8104 & 0,8362 & 0,2878 & 0,2928 \\
\hline & \multicolumn{5}{|c}{ Interaction between the times $\mathrm{T}^{1}$ and $\mathrm{T}^{2}$} \\
in the different solutions (p values) \\
\hline Solution & \multicolumn{3}{|c|}{ Silicon } & Zirconium & Calcium \\
\hline Distilled water & 0,1480 & \multicolumn{2}{c|}{0,0103} & 0,2357 \\
\hline Redbull & 0,0471 & 0,0740 & 0,4971 \\
\hline Monster & 0,3632 & 0,3296 & 0,5040 \\
\hline
\end{tabular}

\section{Discussion}

The results obtained by spectrometry presented as load constituents of the composite resin Filtek Z350XT: magnesium, aluminum, silicon, potassium, calcium, iron, zinc and zirconium, in agreement with the work of Asaka et al., where the load of eight resins was evaluated, using the same method, and 20 chemical elements were identified in different composite resins (Beautifil, Esthet-X, Point 4, Clearfil ST, Solare Solare P, InTen-S Filtek Supreme) [14]. In the Asaka study, Filtek Z350XT resin was not studied and it differs from the resins evaluated in the author's study by the presence of magnesium and by presenting zirconium as the highest concentration of inorganic particles. The distilled water did not interfere in the load of the evaluated chemical elements. Similar in vitro studies also used distilled water as a control group to assess the interference of acidic media in various resin properties, such as: color stability, changes in surface roughness, microhardness and resistance to flexion $[2,7,10,15]$. 
The properties of composite resins, once altered, result in deformation in the composition of the material, since the erosive effect of the acid medium acts by degrading the resin matrix and exposing these particles, something that directly implies the surface roughness of the composite resin and, subsequently, in its microhardness [16]. Energy drinks, according to the work of Cavalcanti et al., have a very acid $\mathrm{pH}$, ranging from 1.52 to 5.5 , which would be a direct cause, for the long-term, solubilization of inorganic content [7]. Silicon (Si) corresponds to silica, found in dispersed form or in silica-zirconia nanocomplexes, which have been mentioned in some studies as fundamental to the mechanical strength of composite resin materials [17, 18]. Here, the elements $\mathrm{Si}, \mathrm{Zr}$ and $\mathrm{Ca}$, of the composite resin (Filtek Z350XT), solubilized, which suggests a possible reduction in the mechanical strength of the material.

There are many studies evaluating the negative effects of the Red Bull energy drink on the color stability of composite resins. The study by Ahmadizenouz et al., have investigated the effects of two energy drinks (Hype and Red Bull), on color change $(\Delta \mathrm{E})$ of two methacrylate-based (Filtek Z250 - 3M; Filtek Z350XT - 3M) and a silorane-based composite resin (Filtek P90 - 3M) after 7 and 30 days, and the results showed that a prolonged immersion time in all solutions increased $\Delta \mathrm{E}$ values of all composites [1]. In the study of Erdemir et al., the effects of sports and energy drinks were evaluated on the surface hardness of different restorative materials (Compoglass F-Ivoclar Vivadent; Filtek Z250 - 3M; Filtek Supreme - 3M and Premise - Kerr) [10].

Surface hardness was measured at baseline, after 1 week, 1 month and 6 months. Surface hardness of all restorative materials was significantly affected by both immersion solution and immersion period. All tested solutions induced significant reduction in surface hardness of the restorative materials over a 6-month immersion period. Additionally, even when composite resin materials are exposed to energy drinks for a short-term period (one month) a significantly decreased surface hardness is expected [19]. The methodology of these theses researches differs from that used in the present study by the time of exposure of the specimens to the solutions, being one hour a day. Nevertheless, the achieved results have shown a meaning reduction in the content of the chemical elements of the composite resin exposed to energy beverages, even with short-term period to acid exposition.

The Monster energy drink, despite being a $\mathrm{pH}=3.65$ drink, similar to RedBull (pH 3.67), did not show statistically significant variations in the elements $\mathrm{Zr}$ and $\mathrm{Ca}$ in the Filtek Z350XT resin. Considering the influence of inorganic filler particles in the physicochemical and mechanical properties of composites, it is essential for the dental surgeon to reinforce the awareness of patients after the restorative treatment, regarding the risks of excessive consumption of energy drinks (beverages with acidic character), for the maintenance and treatment longevity.

\section{Conclusion}

A solubilization can compromise the properties of the composite resin in the long term. In the inorganic chemical quantification of Filtek Z350XT composite resin, the most prevalent chemical elements were zirconium, silicon and calcium, components that provide resistance to the material. Additionally, the results have shown a significant reduced concentration to these elements after energy drinks challenge exposition, especially with Red Bull. Nevertheless, it is also suggested to carry out new studies, with other types of composite resins, as only nanoparticulate composite resin was used in the present study.

\section{Conflicts of Interest}

None.

\section{Acknowledgements}

We thank the Foundation Support of Research the State of Amazonas, FAPEAM, for the award of the scientific initiation grant, during the research developed in 2018-2019.

\section{REFERENCES}

1. Ghazaleh Ahmadizenouz, Behnaz Esmaeili, Zohreh Ahangari, Soraya Khafri, Aghil Rahmani (2016) Effect of Energy Drinks on Discoloration of Silorane and Dimethacrylate-Based Composite Resins. J Dent 13: 261-270. [Crossref]

2. Maria Luísa de Alencar E Silva Leite, Fábia Danielle Sales da Cunha Medeiros E Silva, Sônia Saeger Meireles, Rosângela Marques Duarte, Ana Karina Maciel Andrade (2014) The effect of drinks on color stability and surface roughness of nanocomposites. Eur J Dent 8: 330336. [Crossref]

3. Ji Won Choi, Myung Jin Lee, Sang Hwan Oh, Kwang Mahn Kim (2019) Changes in the physical properties and color stability of aesthetic restorative materials caused by various beverages. Dent Mater J 38: 33-40. [Crossref]

4. Claudio Poggio, Matteo Viola, Maria Mirando, Marco Chiesa, Riccardo Beltrami et al. (2018) Microhardness of different esthetic restorative materials: Evaluation and comparison after exposure to acidic drink. Dent Res J (Isfahan) 15: 166-172. [Crossref]

5. Oliver Clapp, Maria Z Morgan, Ruth M Fairchild (2019) The top five selling UK energy drinks: implications for dental and general health. $\mathrm{Br}$ Dent J 226: 493-497. [Crossref]

6. Martha Carmen Ballistreri, Clarissa Mendonça Corradi Webster (2008) Consumption of energy drinks among physical education students. Rev Lat Am Enfermagem 16: 558-564. [Crossref]

7. A L Cavalcanti, M Costa Oliveira, V G Florentino, J A dos Santos, F F Vieira et al. (2010) Short communication: in vitro assessment of erosive potencial of energy drinks. Eur Arch Paediatr Dent 11: 253-255. [Crossref]

8. P Sarveshwar Reddy, K L Sunil Tejaswi, Suneeth Shetty, B M Annapoorna, Sudarshan C Pujari et al. (2013) Thippeswamy HM. Effects of commonly consumed beverages on surface roughness and color stability of the nano, microhybrid and hybrid composite resins: an in vitro study. J Contemp Dent Pract 14: 718-723. [Crossref]

9. Shabna Moyin, Banibrata Lahiri, George Sam, Preethi Nagdev, Neelagiri Nitish Kumar (2020) Evaluation of the Impact of Acidic Drink on the Microhardness of Different Esthetic Restorative Materials: An In Vitro Study. J Contemp Dent Pract 21: 233-237. [Crossref]

10. Ugur Erdemir, Esra Yildiz, Meltem Mert Eren, Sevda Ozel (2012) Surface hardness of diferente restorative materials after long-term immersion in sports and Energy Drinks. Dent Mater J 31: 729-736. [Crossref] 
11. Luc D Randolph, William M Palin, Gaëtane Leloup, Julian G Leprince (2016) Filler characteristics of modern dental resin composites and their influence on physico-mechanical properties. Dent Mater 32: 1586-1599. [Crossref]

12. H Alzraikat, M F Burrow, G A Maghaireh, N A Taha (2018) Nanofilled Resin Composite Properties and Clinical Performance: A Review. Oper Dent 43: E173-E190. [Crossref]

13. José Eduardo Pelizon Pelino, Alan Passero, Airton Abrahao Martin, Christine Ann Charles (2018) In vitro effects of alcohol-containing mouthwashes on human enamel and restorative materials. Braz Oral Res 32: e25. [Crossref]

14. Youhei Asaka, Masashi Miyazaki, Hirofumi Aboshi, Takeshi Yoshida, Toshiki Takamizawa et al. (2004) EDX fluorescence analysis and SEM observations of resin composites. J Oral Sci 46: 143-148. [Crossref]

15. Khalid H Al Samadani (2013) Effect of energy drinks on the surface texture of nanofilled composite resin. J Contemp Dent Pract 14: 830835. [Crossref]
16. Marília de Morais Pinelli, Anderson Catelan, Luís Felipe Marques de Resende, Luís Eduardo Silva Soares, Flávio Henrique Baggio Aguiar et al. (2019) Chemical composition and Roughness of enamel and composite after bleaching, acidic beverages and toothbrushing. J Clin Exp Dent 11: e1175-e1180. [Crossref]

17. Ibrahim M Hamouda (2011) Effects of various beverages on hardness, roughness, and solubility of Esthetic restorative materials. $J$ Esthet Restor Dent 23: 315-322. [Crossref]

18. R L Bowen (1963) Properties of a silica-reinforced polymer for dental restoration. J Am Dent Assoc 66: 57-64. [Crossref]

19. Ugur Erdemir, Esra Yildiz, Meltem Mert Eren, Sevda Ozel (2013) Surface hardness evaluation of different composite resin materials: Influence of sports and energy drinks immersion after a short-term period. J Appl Oral Sci 21: 124-131. [Crossref] 